\title{
Teoría y práctica de la "patria intelectual". La comunidad transatlántica en la conjunción de cartas, revistas y viajes
}

\author{
Dr. Claudio Maíz*
}

\section{Resumen:}

En el presente trabajo nos hemos propuesto la descripción de una comunidad imaginada, que con el nombre de "patria intelectual" (concepto acuñado por José Enrique Rodó) tuvo vigencia durante las postrimerías del siglo XIX y comienzos del XX. Esta comunidad intelectual imaginada tiene un carácter transatlántico en el que se reúnen tanto las expresiones literarias españolas como las hispanoamericanas. La metodología que nos ha permitido la tarea es la de las redes intelectuales, ya que esta comunidad se configura a través de cartas, revistas, citaciones mutuas, viajes, todos instrumentos propios de los sistemas de religación presentes en una red.

Palabras clave: redes intelectuales, comunidad imaginada transatlántica, historia literaria

\section{Abstract:}

In the present work we proposed a description of an imagined community, which under the name of "homeland intellectual" (a concept coined by Jose Enrique Rodó) took effect during the late nineteenth century and early XX. This imagined intellectual community has a transatlantic bringing together both Spanish literary expressions as Hispano-Americans. The methodology has enabled us to the task is that of intellectual networks, as this community is configured through letters, journals, mutual citations, trips, all instruments own systems relegation in a network.

Key words: Networks intellectuals, imagined community transatlantic literary history

* Investigador argentino. Profesor de Literatura hispanoamericana de la Universidad Nacional de Cuyo Miembro del Consejo Nacional de Investigaciones Científicas y Técnicas.cmaiz@logos.uncu.edu.ar 
Teoría y práctica de la "patria intelectual". La comunidad transantlántica en la conjunción de cartas, revistas y viajes / Dr. Claudio Maíz

\section{Redes y espacios de pertenencia}

Como se sabe, las historias literarias hispanoamericanas, desde el siglo XIX, estuvieron compuestas de manera excluyente a partir de la centralidad del estado-nación. Esta particularidad produjo algunos aislamientos y distorsiones, por un lado, el estudio de las voces literarias nacionales separadas del contexto de América Hispánica y, por otro, la consideración de la literatura como una expresión de la nacionalidad, exacerbando el rasgo anterior. ${ }^{1}$ Al margen de las ideologías liberal o conservadora que caracterizó el siglo XIX, el rasgo indicado se continuó cultivando incluso durante el siglo XX bajo otras modalidades. En general, la lógica constructiva de la historiografía cultural, entendida en sentido amplio, con centro en el estado-nación no ha encontrado ningún beneficio en los intentos relacionales, como en el caso de la literatura -lo mismo vale para el arte, las ideas, la historia política-, por ese motivo no se han emprendido exploraciones en tal sentido, si no unas muy escasas y recientes. ${ }^{2}$ De ahí que una pregunta orientada a la incidencia que tienen las redes, es decir, los dispositivos de religación que utilizan los intelectuales, sobre el diseño de las comunidades imaginadas aún no tiene respuesta satisfactoria. La constatación es paradójica, ya que también las nacionalidades, a las que tan adeptas han sido las historiografías, se han configurado mediante la acción de las redes intelectuales, entre otros factores. Pese a que Benedict Anderson (Anderson, 1997) detectó la fuerza cohesiva del nacionalismo para la existencia de una comunidad, no reparó en el poder de las redes en la formación imaginaria de la comunidad. Su teoría de base cultural del nacionalismo se centró en el desarrollo industrial, la alfabetización y la reducción del costo de la imprenta; todo lo cual hizo accesible los diarios y semanarios al gran público. De esa forma la información, los símbolos y las historias compartidas provocaron sentimientos de vincu-

2 En el ámbito de las historias de las ideas debe destacarse la obra de Eduardo DevésValdés (Devés-Valdés, 2007). V. también (Arpini, Maíz, 2007) 
lación y solidaridad entre los miembros de un mismo territorio sin que necesariamente llegaran siquiera a conocerse.

En vista de estas carencias, qué es lo que habría que subsanar. En principio, la ausencia de cruce entre las dimensiones referidas a los medios, entre los que se halla la red, y los campos configurativos, a fin de obtener, sospechamos, novedosos frutos, como por ejemplo los espacios de legitimación y proyección pública (Molina, 2007), de reunión y circulación modernas (Naciff, 2007), de encuentro, refugio y amparo durante los exilios (Paredes, 2007), por mencionar solamente algunos posibles resultados. La metodología de las redes contribuye, en suma, a revelar en el estudio de los fenómenos intelectuales algunas dimensiones que, desde otras perspectivas, o no emergen con claridad o parecen poco satisfactorias. Mucho antes del desarrollo de las teorías polisistémicas (Even-Zohar, 1997), Alfonso Reyes ponía en práctica la idea de las relaciones intelectuales como un imperativo del conocimiento recíproco:

Relacionad, pues, a nuestros hombres de pensamiento unos con otros. Sed ingeniosos e incansables; discurrid medios para crear los vasos comunicantes; labor de prensa, correspondencia, obligación de cambios de libros a través de organismos adecuados, exposiciones de arte, de conciertos, viajes de profesores y estudiantes, congresos de escritores, sistemas de investigación paralela! Qué sé yo! (Reyes, 1959: 70)

Es necesario, entonces, fijarse un horizonte metodológico que vaya más allá de la centralidad del estado-nación y los respectivos paradigmas que lo sostienen. Pero para que el propósito relacional se complete, se hace necesario ir más allá de la noción de generaciones y también más allá de la idea de lugar, ambos como principios estructurantes de las historiografías. Admitimos desde luego que estas tres dimensiones: nación, generación y lugar están en crisis; estos principios nos ha impedido comprender de manera más transversal la producción cultural iberoamericana en su relación con Europa, por caso. A la nación es factible confrontarla con la red transatlántica, a la generación con la tendencia, en lugar del factor etario y al lugar con los nuevos contextos que ofrece 
Teoría y práctica de la "patria intelectual". La comunidad transantlántica en la conjunción de cartas, revistas y viajes / Dr. Claudio Maíz

la lógica de enlace de la redes. ${ }^{3}$ Así las cosas, ¿la imaginación de una comunidad constituye un hecho aislado, individual, propio, o bien se forja en la intercomunicación con otros sujetos? La respuesta puede parecer obvia, sin embargo a poco de andar descubrimos que, pese a considerarse comunitaria, no hay análisis de la manera como la imaginación trabaja, en qué ámbitos se realiza y de qué medios se vale para tales fines y cuáles son los resultados. La configuración de una comunidad imaginada alcanza dimensiones limitadas cuando se trata del paradigma nacional, aunque también puede pensarse la comunidad imaginada en una dimensión superior, como la que presentan algunas elites intelectuales. ¿El sentido de pertenencia es siempre el mismo o varía de acuerdo a las redes y las condiciones en las que éstas se originan? Las redes intelectuales del siglo $\mathrm{XIX}$, si se toma en cuenta la fuerte impronta política que anima a algunas de ellas, como por ejemplo la de los "proscriptos" liberales durante el gobierno de Juan Manuel de Rosas en la Argentina, no parecen demasiado similares a las de comienzos del siglo XX, en momentos de la autonomía del arte, la especialización de la política y un intenso cosmopolitismo. Con todo, el principal punto común que poseen es haber trabajado por fuera de las fronteras nacionales. Este es el dato más relevante.

3 Por otra parte, un estudio que también ofrece algún interés es el de Guillermo Díaz Plaja, Al filo del novecientos. Estudios de intercomunicación hispánica. El libro, aunque desactualizado en algunos métodos, se ocupa de una serie de temas que, cronológicamente, se ubican en las primeras décadas del siglo XX. El crítico español entiende por "estudios de intercomunicación hispánica" al amplio "juego de mutuas penetraciones entre las culturas que más nos importan", es decir, "los movimientos espirituales, entre España y América". Entre ambos espacios se produce un ejemplo de "mutuas curiosidades y asimilaciones que, posteriormente, no han continuado en tan estrecha estimación. De ahí el aspecto de ejemplaridad que desearía que tuviera este libro" (Ibidem). Esta nota aclaratoria es suficientemente ilustrativa, nos parece, de que el fenómeno de recíproca implicancia dentro de un contexto hispánico no tiene precedentes ni tampoco tendrá continuidad, si no quizás hasta la emergencia del "boom" latinoamericano, y aun así, ya no con la intensidad que tuvo a comienzos del siglo XX. (Díaz Plaja, 1971). Otro estudio digno de destacar pertenece a Emilia de Zuleta, Relaciones literarias entre España y la Argentina. Como se ve, se trata de una investigación que está ceñida a una relación entre dos naciones: España y Argentina, lo cual marca una diferencia con respecto a los dos estudios anteriores, que pretenden visiones más abarcadoras. Podría decirse que operan concepciones dispares entre estas investigaciones. Asimismo, el trabajo de Zuleta se limita a un objetivo claramente definido: la presencia de las letras españolas en la Argentina, a través de las revistas literarias. Para ello se ocupa de diez revistas argentinas que abarcan un período que va de la iniciación de Nosotros [1907] al cierre de Realidad [1949], a través de tres ciclos: 1907-1926, 1927-1935 y 1936-1948. Entre las conclusiones generales de su recorrido, cabe destacar la individualización de quiénes sirvieron de "mediadores en el intercambio de información, y en las diversas formas de acercamiento", así como también la revelación de cómo se llevaron a cabo las modalidades de esta labor, que van del carácter ocasional (aniversarios, viajes, episodios polémicos) al orgánico (la investigación erudita, el ensayo, la crítica periodística, la información bibliográfica) Finalmente, pone de relieve el porqué de estas interrelaciones, "desde las afinidades de índole estética hasta las motivaciones de orden ideológico, político o económico"19. En suma, los estudios mencionados dan cuenta de una intercomunicación cultural entre áreas espaciales que están conectadas tanto por la lengua como por las redes intelectuales. (Zuleta, 1983) 
Nuestra hipótesis de trabajo, en tal sentido, consiste en plantear que entre 1898-1920 aproximadamente se constituye una comunidad imaginada más allá de las fronteras nacionales de Hispanoamérica y más allá aun del obstáculo geográfico que representa el Océano Atlántico. Afirmamos que se trata de la primera comunidad imaginada intraamericana y transatlántica con un fuerte anclaje en la lengua como nexo de unión y entendimiento. Este espacio ideal no está regimentado por una idea de unión continental hispanoamericana, cuyo origen se remonta a los tiempos de los libertadores (Simón Bolívar, el más destacado), y de los intelectuales republicanos (Andrés Bello, Simón Rodríguez), ni tampoco por un hispanismo hegemónico (con sentido regenerativo de una ideología monárquica y católica, como lo llegó a ser durante la era del franquismo). Tampoco se trata de acuerdos interestatales o acciones llevadas a cabo por actores de ese sector (económicos, diplomáticos, financieros, etc.), ni de clases, algo así como una internacional hispana de obreros, campesinos o artesanos. Esta primera comunidad intelectual imaginada no fue sencillamente el resultado espontáneo de un conjunto de voluntades, sino la consecuencia de una labor precisa, como podrá observarse más adelante.

¿Cuáles fueron las motivaciones que impulsaron a estos intelectuales para la formación de espacio de religación? Enumeremos algunas: a. La ampliación de fronteras intelectuales para los hispanoamericanos; b. La ampliación de públicos para los españoles e hispanoamericanos; c. Enfrentamiento -con éxito- del dilema del confinamiento nacional o la propagación de las fronteras en pos de porciones de universalidad (más para los hispanoamericanos que españoles); d. Desde el punto de vista español, América representaba una salida a la crisis del 98; e. Desde el punto de vista hispanoamericano, España constituía el punto de ingreso a Europa. Concientes de los recortes que practicamos, esta presentación persigue la finalidad de bosquejar un modelo inteligible que contribuya a enlazar la configuración de la comunidad intelectual imaginada y los medios a través de los cuales llega a constituirse (cartas, revistas, viajes). El saldo más palpable de la intercomunicación entre España y América, por un lado, y entre los países hispanoamericanos entre sí, por otro, fue el forjamiento de la "patria intelectual", un lugar ideal en que los hombres letrados podían no sólo conectarse entre sí, sino además elaborar visiones, pulir ideas, proyectar programas con vistas a crear una sociedad de hombres agrupados por el uso de un común instrumento: la lengua.

La actividad que caracteriza a la "patria intelectual", en consecuencia, forma parte de la historia de las relaciones culturales establecidas entre españoles e hispanoamericanos y estos últimos entre sí. El historiador Carlos Rama ha estudiado tales vínculos, centrándose en el siglo XIX, no obstante, entre los propósitos perseguidos figura el dar respuestas 
Teoría y práctica de la "patria intelectual". La comunidad transantlántica en la conjunción de cartas, revistas y viajes / Dr. Claudio Maíz

a los interrogantes sobre cómo y de qué forma se han dado los lazos entre intelectuales, se han intercambiado experiencias y creaciones $y$, fundamentalmente, cómo y en qué forma se han influido entre sí y han participado en la cultura internacional. (Rama, 1982: 12-13) Las transformaciones tecnológicas y las instituciones correspondientes presentan una extraordinaria diferencia si se compara con el nivel tecnológico y las instituciones existentes a comienzos del siglo XX. ${ }^{4}$ En punto, entonces, a las transacciones culturales se ha producido el tránsito de "una lenta influencia" -comienzos del siglo XX-, a "una transmisión inmediata" en la actualidad. El arte moderno, tal como se entendió a comienzos del siglo $X X$, contaba como medios expresivos a la escritura, la pintura, la escultura y el teatro, por tanto los espacios privilegiados eran las salas teatrales, las galerías, las exposiciones, los periódicos, etc. El contraste con la cultura contemporánea es evidente, pues, sin que se hayan sustituido los medios anteriores, han adquirido un relieve extraordinario el cine, la televisión, la radio, etc. ${ }^{5}$ De manera que la idea de que al desarrollo tecnológico, de comienzos del siglo XX, le corresponde un modo especial de contacto, entendido como de una "lenta influencia", resulta la más conveniente para el enfoque de la red que la coalición conformada por los intelectuales del 98 español y el 900 hispano-americana.

Carlos Rama afirma que "si extensos son estos asuntos culturales, están, a su vez, limitados y condicionados por la estructura socioeconómica y los aparatos políticos". (Rama, 1982: 13) Esto último, según entendemos, es parcialmente cierto. No caben dudas de que tanto las estructuras económicas y los aparatos políticos cumplen un papel significativo, pero si nos sujetamos a ellos no encontraríamos explicaciones para el desbordamiento de esas contenciones que las relaciones culturales terminan produciendo. Aún más, al declinar la centralidad conferida a los estados nacionales es posible pensar en otros términos

$4 \quad$ Sin embargo, como piensa Zanetti algunas condiciones estructurales son necesarias para que tuvieran lugar los fenómenos de religación: "El proceso modernizador no determinó la constelación de artistas e intelectuales del período, pero fue condición imprescindible para que fuera posible un movimiento mancomunado en concepciones estéticas e ideologías, para que surgiera el intercambio y la discusión entre pares, medianamente generalizada y con cierta simultaneidad. La religación, en sus numerosas variables, supone la quiebra del aislamiento, del comportamiento estanco, y para ello hacían falta bases materiales para vehiculizarla y una mentalidad moderna." (Zanetti, 1994: 500).

5 Al decir de Williams, todavía algunos reservan las categorías de "arte" o "las artes" para las primeras tecnologías e instituciones (escritura, pintura, escultura, teatro, etc.) con una asociación constante con la metrópoli en tanto centro. Sin embargo, los verdaderos medios modernos son de una clase diferente. Por otro lado, la idea de metrópoli ha cambiado en la extensión de un mercado organizado y global de las nuevas tecnologías culturales. Hoy, la verdadera metrópoli, es la trasmisora de las economías técnicamente avanzadas y dominantes. (WILLIAMS, 1989: 58). 
los intercambios culturales, fuera incluso de lo que se entiende como "relaciones internacionales"6.

\title{
II. La comunidad intelectual imaginada
}

\section{Rodó y la "patria intelectual"}

La comunidad intelectual imaginada hacia fines del siglo XIX y comienzos del XX recibió el nombre de "patria intelectual" en contraposición de la "patria real", que es política, limitada, celosa de su soberanía. La "patria intelectual" la vislumbró el uruguayo José Enrique Rodó, que la concibió como un lugar ideal, en razón de que "las fronteras del mapa no son las de la geografía del espíritu". Rodó escribía, hacia 1896, en un ensayo titulado "La novela nueva. A propósito de "Academias", de Carlos Reyles":

\begin{abstract}
Parecerá punible a los que defienden como el sagrado símbolo de la nacionalidad intelectual, el aislamiento receloso y estrecho, la fiereza de la independencia literaria que sólo da de sí una originalidad obtenida al precio de la incomunicación y la ignorancia candorosa; parecerá punible a los huraños de la existencia colectiva, a quienes es necesario convencer de que la imagen ideal del pensamiento no está en la raíz que se soterra, sino en la copa desplegada a los aires, y de que las fronteras del mapa no son las de la geografía del espíritu, y de que la patria intelectual no es el terruño. (Rodó, 1967: 156)
\end{abstract}

Rodó hace referencia a las censuras que habría de recibir la obra de Carlos Reyles por atreverse a adaptar "la novela nueva" que prevalece en las literaturas del mundo a sus propios relatos. Pero a diferencia de otros intelectuales que se expresan en favor de la constitución de un espacio trasnacional, Rodó además de hacerlo le confiere supremacía a las literaturas metropolitanas, por medio de un "derecho" a la conducción, al que las producciones hispanoamericanas (y otras no centrales) deberían subordinarse:

Todo propósito de autonomía literaria que no empiece por reconocer la necesidad de la vinculación fundamental de nuestro espíritu con el de los pueblos a quienes pertenece

\footnotetext{
"En el curso de los últimos años, la pérdida aparente de centralidad de los estados nacionales ha ayudado a hacer manifiesta la complejidad inherente a los procesos reintercambio cultural oculta tras una perspectiva que tendió a concebir los mismo exclusivamente en términos de relaciones internacionales." (Palti, 2004: 8).
} 
Teoría y práctica de la "patria intelectual". La comunidad transantlántica en la conjunción de cartas, revistas y viajes / Dr. Claudio Maíz

el derecho de la iniciativa y de la dirección, por la fuerza y la originalidad del pensamiento, será, además de inútil, estrecho y engañoso. (Rodó, 1967, 162)

Sin embargo, un poco más adelante disuelve la prelacía antes conferida en una "universal confederación de almas". Aunque todo ello es en apariencia:

Mal aislador es el agua del Océano para la corriente que hace vibrar, con el impulso lanzado a toda hora desde los centros donde se condensa y suena la hirviente espuma de la vida, la inmensa red nerviosa que el genio de una misma civilización extiende del uno al otro extremo del planeta por una universal confederación de almas. (Rodó, 1967, 162)

Con todo, el pasaje es interesante ya que la búsqueda de la autonomía aunque esté sujeta al requisito de la subordinación no es posible sino a través de una "inmensa red" extendida por todo el planeta.

\section{Manuel Ugarte: la solidaridad hispanoamericana}

La "patria intelectual", por cierto, no es una noción unívoca, a pesar de que existe una clara coincidencia general en la necesidad de sobreponerse a los confinamientos locales, tal como sugieren estas preguntas de Manuel Ugarte: "Pero, mi patria, ¿es acaso el barrio en que vivo, la casa en que me alojo, la habitación en que duermo? ¿No tenemos más bandera que la sombra del campanario?" Las diferencias de Ugarte emergen con toda claridad al momento de definir la "patria superior", que se ve como "el conjunto de ideas, de recuerdos, de costumbres, de orientaciones y de esperanzas que los hombres del mismo origen, nacidos de la misma revolución, articulan en el mismo continente con ayuda de la misma lengua." Como se observa, la idea de la nacionalidad no está anudada sino a una representación imaginaria en la que la gravitación de la lengua es esencial. No está en las "convenciones" la manera de mediar la constitución de la "patria superior"; más bien en el "parecido" de la "realidad viviente de las cosas" americanas. La mayor diferencia con Rodó aflora en que para el uruguayo la existencia de las cosas americanas se subordina a un centro que las orienta, admitiendo un supuesto espíritu de concordancia en el concierto mundial de los pueblos y naciones, en Ugarte la percepción, sin embargo, es de desconfianza por el "peligro" que suponen las naciones poderosas. Esta circunstancia se constata "cuando siento que otra raza nos arrolla y nos empuja hacia el sur" y

/.../ lejos de limitarme a comprobar que mis fronteras inmediatas están indemnes, levanto el espíritu hacia más 
altas concepciones, abarco la plenitud del conflicto y me solidarizo con los de mi grupo, convencido de que al defender la integridad de otras repúblicas, defiendo no sólo el alma y la razón de ser de la mía, sino también la fuerza y el provenir de los 80 millones de hombres que aquí se expresan en español. (Ugarte, 1922,148)

De manera que la concepción superior de la "patria" constituye un recurso defensivo y no meramente integrado a la "confederación universal de almas" como imaginaba Rodó. Aun con estas diferencias y otras, la comunidad imaginada por las elites intelectuales resulta un espacio imprescindible, ya que incluye instituciones, academias, ateneos, salas de redacción de periódicos, revistas, encuentros, viajes, conferencias, banquetes, asociaciones locales e internacionales e incluso agremiaciones intelectuales.

\title{
3. Rubén Darío y la "confraternidad espiritual internacional"
}

\begin{abstract}
En los últimos movimientos de ideas que se han desarrollado y han triunfado en el mundo literario, ha habido entre los luchadores quienes han sido intermediarios entre los grupos pensantes, iniciadores de relaciones, propagadores, vinculadores, anunciadores, introductores de espíritus humanos o de obras afines. /.../Y mérito innegable y siempre digno de reconocimiento será el de los que, a más de la realización de sus personales ambiciones, han contribuido a esa especie de confraternidad espiritual internacional que ha sido uno de los distintivos especiales de la evolución que se inició en Francia con el nombre de simbolismo y que, alcanzando hasta nosotros después de otros "ismos", dio por resultado un nuevo triunfo para el arte humano y el definitivo reconocimiento del poder de la libertad y de la individualidad.(Darío, 1951, 112)
\end{abstract}

Debe llamarse la atención sobre el hecho de que la cita anterior corresponde a un texto titulado "El Brasil intelectual", es decir, el poeta nicaragüense no habla de lo que más cercanamente conoce sino de un espacio intelectual para él relativamente poco conocido, familiaridad en la que se debe computar desde luego su viaje a Río de Janeiro a propósito de una conferencia panamericana realizada a comienzos del siglo $\mathrm{XX}$, a la que asiste como representante. En otras palabras, su idea de un "confraternidad espiritual internacional" es verdaderamente abierta y plausiblemente internacional a diferencia de otras especies de "internacionalismos" centrales, algo que veremos más adelante. Algo más: Darío elabora un listado de nombres, cuyo detalle le resta una aparente 
Teoría y práctica de la "patria intelectual". La comunidad transantlántica en la conjunción de cartas, revistas y viajes / Dr. Claudio Maíz

espontaneidad a la labor de cultura, dándole por el contrario un carácter premeditado. Estos hombres de letras actúan como propagadores e intermediarios entre las "elites más o menos numerosas", afirma el poeta. Estos son algunos de los nombres: Elysio de Carvalho en el Brasil; Pedro Emilio Coll y Pedro César Dominici en Venezuela; José Juan Tablada y el grupo de la Revista Azul y de la Revista Moderna; Luis Berisso, Jaimes Freyre y Díaz Romero en Argentina; Rodó y Pérez Petit, en el Uruguay, entre otros nombres y sus respectivos países. (Darío, 1951, 112) En el fondo la lista que Darío confecciona la hace pensando en los diseminadores del movimiento modernista que él encabezaba. A la postre, modernismo y transnacionalidad tenían mucho más que ciertas convergencias, en algunos discursos formaban parte de un mismo emblema. ¿Dentro de qué coordenadas espaciales trabajan estas voluntades? Ni más ni menos que transatlánticas, gracias a lo cual se hace factible hablar de una literatura de "carácter inconfundible en su variedad" pero que conjuga "la Joven España y la Joven América española". (Darío, 1951, 117)

\section{Religación y literatura hispanoamericana}

Dos rasgos sobresalen en la caracterización de la "patria intelectual". En primer lugar, debe descartarse cualquier relación directa con el poder, es decir esta comunidad imaginada no representa de manera directa los lazos vinculantes entre el estado y los intelectuales. Por ello cabe sugerir que la "patria intelectual" guarda escasos puntos de contacto con la ciudad letrada instituida según los términos en los que la definió Ángel Rama -propietaria de la letra en función del ejercicio de un poder- (Rama, 1985), se trata más bien de una tentativa, por un lado, de inclusión y, por otro, de construcción de una comunidad intelectual que se debate entre la autonomía y la dependencia estatal. En suma, el ámbito en el que se desenvuelve esta comunidad imaginada es el intelectual, artístico, letrado, ni siquiera universitario (aunque hubo iniciativas desde este sector). En segundo lugar, en el centro de esta comunidad imaginada se ubica la dilucidación de lo abierto o lo cerrado -para decirlo en términos matriciales-, como posiciones que se definen en contraposición con la cultura europea. En cierto modo la "patria intelectual" sigue conservando aquel dualismo que Ángel Rama vio entre la ciudad letrada y la ciudad real. Aunque nos parece que en el caso que tratamos la dualidad no pretende ser una mera sustitución de la realidad por el signo, como lo persiguió la ciudad letrada, sino la creación de un espacio utópico, levantado como promesa de realización futura. En otros términos, la imaginación de una comunidad alejada de las fronteras políticas actuaría como divisa hasta hacer confluir la "patria superior", que es continental e iberoamericana, con la "patria nacional". 
No es por cierto una "patria" a la que tiene acceso el 'demos', ni tampoco se trata de una aristocracia, aunque no falten algunos que así lo deseen. Para formar parte de ella se requiere el cultivo de la inteligencia, el ejercicio de las letras y una mínima noción de solidaridad. La "patria intelectual" puede pensarse asimismo como antítesis de la "República Mundial de las Letras", que tiene su capital en París. Se trata de otro espacio simbólico que no se rige por un sistema "transparente", sino que su régimen es "despótico", ya que abre y cierra sus ingresos al compás de sus propios intereses. Decimos que estos espacios simbólicos se contrastan puesto que uno -la "patria intelectual"- nace como una necesidad de contener a los intelectuales periféricos, impedidos, muchos de ellos, de ingresar a la "República Mundial de las Letras". De modo que no es tan sólo mediadora la función que cumplen los espacios imaginados, como dice Gramuglio que "por su misma formación cultural, las elites intelectuales ocupan una posición estructuralmente mediadora, entre el "megasistema" de la "República mundial de las letras" y los polisistemas locales a que pertenecen." (Gramuglio, 2006) Aún más, para nosotros existiría una voluntad de procrear una instancia alternativa a la "república mundial". La "patria intelectual" es el resultado de un instancia coyuntural precisa en el tiempo, que según nuestra hipótesis no reconoce antecedentes ni volverá a repetirse en el futuro. Se trata de una forma especial de imaginación que combinó el espacio, la lengua, la actividad intelectual y los medios técnicos conocidos. Uno de cuyos resultados fue la fundación de la literatura hispanoamericana como entidad autónoma de España (en rigor, el intento venía desde el romanticismo) tanto como de los centros de gravedad nacionales. Es interesante la reconstrucción -llevada a cabo por Susana Zanetti- de los circuitos mediante los cuales se alcanza un grado de autoconciencia estética que permite hablar de la fundación de la literatura hispanoamericana. A dicha autoconciencia se llega gracias a lo que la investigadora llama "fenómenos de religación", que son lazos efectivos tendidos más allá de las fronteras nacionales en "un entramado que privilegia ciertas metrópolis, determinados textos y figuras, que operan como parámetros globalizantes, como agentes de integración." Para el análisis de estos fenómenos se hace necesario "anudar detalles y vertebrando encuentros, lecturas, correspondencia -múltiples vínculos, en fin-el estudio de la religación intenta contribuir a la respuesta de cómo se fue constituyendo y fortaleciendo esa amalgama que subyace en la construcción del objeto que denominamos literatura latinoamericana" (Zanetti, 1994, 491). Zanetti ha visto que el periodo que va de 1880 a 1916 es altamente significativo desde la óptica de la religación, ya que se empiezan a superar las manifestaciones literarias más o menos aisladas y a organizarse una literatura de intercomunicación a nivel continental. La crítica argentina también es bien precisa en cuanto a la singularidad del momento que estudia, en virtud de que existen pruebas contundentes sobre las diferencias con el ciclo anterior, en el que los vínculos descan- 
Teoría y práctica de la "patria intelectual". La comunidad transantlántica en la conjunción de cartas, revistas y viajes / Dr. Claudio Maíz

saban sobre unos pocos nombres estelares (Bello, Sarmiento y otros) y no tanto sobre las tramas de religación (Zanetti, 1994, 491)7.

La tesis de Zanetti sería que los letrados encaran "su experiencia singular, y nacional -mexicana, colombiana-, desde una dimensión mayor que las contiene y que empieza a reconocer modelos propios.". Dicha dimensión no sería otra que la hispanoamericana, ya que los vínculos con el Brasil son escasos y el Caribe no hispanohablante se lo presiente como muy lejano (Zanetti, 1994, 492). De nuestra parte consideramos que la perspectiva resulta correcta pero insuficiente a la hora de explicitar la manera como el restablecimiento de los vínculos con Europa se convierte en un problema a resolver. Más aún, las religaciones se producen con más fuerza desde Europa, desde diversas sedes: Madrid, Barcelona, París e incluso Salamanca. Estos puntos constituyen nudos cruciales de la red, trama o religación que acontece entre fines del siglo XIX y comienzos del XX. Así lo testimonia, en parte, la correspondencia que está fechada en alguna ciudad europea o norteamericana, proveniente de quienes Zanetti llama "las grandes figuras religadoras": José Martí, Rubén Darío, Manuel Ugarte (Zanetti, 1994, 522). La "patria intelectual" -sostenemos- demanda de centros más "adelantados" ya sea desde el punto de vista técnico, económico o estético. Repárese en que sedes como Nueva York o París son las que estos hispanoamericanos utilizan para lograr la más considerable difusión de sus discursos ${ }^{8}$. Esto no niega la religación intracontinental sino que le confiere otra dimensión. Con todo, Zanetti no deja de reconocer "la importancia de París como polo de religación extracontinental", y ve la necesidad de "insistir en la relevancia de España en este aspecto, en función de que en ella se estrechan relaciones y reconocimientos mutuos de una envergadura inédita luego de la independencia americana" (Zanetti, 1994, 527). El propio Miguel de Unamuno era conciente de ello: "En ciertos respectos -dice- sigue todavía siendo Europa el lazo de unión entre los pueblos americanos." (Unamuno, 1958, 776) Cuando nuestro autor dice Europa, alude también, y especialmente, a Salamanca, como luego lo podremos apreciar. Así y

De acuerdo con la noción historiográfica de Pedro Henríquez Ureña, la literatura hispanoamericana podía organizarse en torno a unos cuantos nombres: Bello, Sarmiento, Montalvo, José Martí, Darío, Rodó. (Henríquez Ureña, 1978: p.47). La breve lista, comenta Susana Zanetti en otra parte, "revela una selección en que se mezclan criterios estéticos con roles 'señeros' de la escritura en función del pensamiento y la organización del estado y de las instituciones culturales americanas". (Zanetti, 1998: p.99).

8 No faltan testimonios que así lo refrendan. Manuel UGARTE en sus memorias Lageneración iberoamericana del 900; o el de GIL ForTOUL: "Si bien en la esfera internacional nuestra América es un todo/... / en literatura cada República tiene aún capilla aparte. Y es difícil pasar de una capilla a otra, separadas como están por distancias enormes y terribles desiertos. Para ir de Buenos Aires a Caracas, lo más corto es venir primero a Europa. Para que un escritor paraguayo conozca personalmente a un colega guatemalteco, lo práctico es venirlo a buscar en los bulevares de París." (Gil Fortoul, 1957: 366). 
todo, esta perspectiva tan interesante no será desarrollada por Zanetti tal como su trascendencia lo amerita.

Para hacer posible una comunidad intelectual de intereses y perspectivas comunes, de origen español e hispanoamericano, se contaba para la época con escasos recursos, visto desde nuestra contemporaneidad: la carta, los periódicos, las revistas y los libros. Medios que además presentaban enormes dificultades de circulación y distribución. A eso se debía sumar las distancias transatlánticas y también intracontinentales en Hispanoamérica, que dificultaban los viajes a punto de hacerlo una actividad excepcional. No obstante lo cual, los viajes existieron y contribuyeron al ensanchamiento imaginario. La comunidad, con todo, se hace realidad, gracias al uso intensivo de estos únicos recursos que tenía a mano.

\section{La nacionalidad lingüística}

La "patria intelectual" se asienta, por un lado, en el conglomerado geo-cultural en el que la lengua es un instrumento de comunicación e interacción, por otro, en algunas mediaciones que permiten la acción lingüística, como por ejemplo, los epistolarios y las publicaciones periódicas. En el cruce de estos factores se producen nuevas representaciones del intercambio cultural, tanto como la configuración de nuevas nociones respecto del rol del intelectual, la nacionalidad como medida de la producción literaria, los centros de poder simbólico, entre otros puntos.

Conviene aclarar que la fusión fuerte de lengua-territorio se corresponde con una etapa precisa de la historia cultural, que es la que aquí se estudia, es decir, la que va de fines del siglo XIX y comienzos del XX, más allá de ella las condiciones comienzan a variar. Entre algunos antecedentes que tienden a proponer espacios transnacionales, aunque con variantes considerables, se puede nombrar la idea de "confederación intelectual o espiritual" expresada en Idearium español de Ángel Ganivet [1896]; los libros y los viajes del historiador Rafael Altamira y Adolfo Posada a América, como una manera de acercamiento entre ambos espacios. Por su parte, la noción de Hispanidad de Unamuno es mucho más que un propósito idealista, consiste en una labor concreta para reunir culturalmente, sobre nuevas bases, a los países que hablan el español.

Creo poder afirmar, -escribe Unamuno para 1912- sin que ello se me tome a petulancia, que yo por mi parte, solo y señero, desligado, sin estatuto ni programa, he hecho por la unión espiritual de los pueblos de lengua española tanto como haya podido hacer cualquier otro y tanto como algunas de estas asociaciones. Hace años que vengo dirigiendo 
Teoría y práctica de la "patria intelectual". La comunidad transantlántica en la conjunción de cartas, revistas y viajes / Dr. Claudio Maíz

mis esfuerzos, entre otras cosas, a que nuestros escritores españoles sean más y mejor conocidos en la América española, y a que sean más y mejor conocidos en España los escritores americanos. (Unamuno, 1958, 467)

Afirmaciones que reitera dos años después en una carta a la Federación Universitaria de Buenos Aires: "uno de mis más constantes desvelos ha sido, es y será el de fraguar relaciones espirituales entre los pueblos todos de lengua castellana" (Unamuno, 1991, 353). Así, la relevancia atribuida a la lengua es a todas luces evidente y está directamente asociada a la capacidad de unir mediante su ejercicio varios conjuntos geoculturales. Pero también la fuerza le proviene de su poder para no estar sometida a las fronteras políticas y, por tanto, a los paradigmas nacionales que las sostienen, pese a que la lengua fue un factor preponderante para el establecimiento de dichos paradigmas. El trazado que la lengua produce recuerda ni más ni menos que a las constelaciones, cuando a partir de un conjunto de estrellas y mediante líneas figuradas sobre la aparente superficie celeste, forman un dibujo que evoca figuras, como la de un animal, un personaje mitológico, etc. En nuestro caso, la figura que emerge es un mapa, inexistente desde el punto de vista del derecho y las convenciones internacionales, es decir, lejos está de constituir una espacialidad reconocida políticamente.

Sin embargo, y a pesar de ello, en el universo de la cultura se recorta como una verdadera nacionalidad, cuyos límites fronterizos se establecen con sumo cuidado, mediante acuerdos simbólicos, alianzas y otros mecanismos. En la "patria intelectual" se habla y escribe en español -americano o peninsular-, se habita un espacio separado por el Océano Atlántico. Que semejante dispersión espacial no haya impedido el diseño de la "patria intelectual" se debe, entre otros motivos, a la existencia de un medio de comunicación común. El resultado cartográfico de la constelación que forma la lengua es un Atlas integrado por España e Hispanoamérica. El valor virtual, al margen de toda legislación positiva, de este Atlas no ha cerrado el paso a la asignación de nombres, como por ejemplo, el de Hispanidad, Iberoamérica, América Latina y se hayan desprendidos de ese tronco algunas ideologías culturales (hispanismo, hispanoamericanismo y otras). Tampoco el Atlas se cierra sobre los dos espacios mencionados sino que se hace extensivo a otros territorios, en el que el español ha sido una lengua dominante (Filipinas). Desde el punto de vista de las condiciones generales que rigen a este Atlas, no debe descartarse que algunas de las problemáticas que lo atraviesan sean de naturaleza semejante a las que acontecen en otras latitudes. Pensamos en las condiciones periféricas, y más particularmente, en las semejanzas observables entre Rusia, España e Hispanoamérica, las dos primeras como periferias europeas y la última como periferia del mundo central desarrollado. 


\title{
V. Los medios: publicaciones, cartas y viajes
}

Por lo visto hasta aquí, se hace impensable la producción de un pensamiento transnacional sobre la literatura (o sobre otras esferas de la cultura) si no es por medio de las redes construidas por los hombres letrados. Las nociones, imágenes, visiones que se configuran en el intercambio, actúan de manera sustitutiva, es decir, cada una de las nociones, imágenes o visiones debe tomarse como una "figura de la imaginación social y política" y no como un objeto de existencia real (Gorelik, 2004, 125). Estaríamos frente a la construcción de objetos supranacionales a través de figuras logradas gracias a redes culturales, que se reconocen de acuerdo con premisas y tiempos precisos. La "patria intelectual" iberoamericana no es sino una figura de la imaginación del intelectual moderno que opera en el ciclo que va de 1898-1920, aproximadamente.

\begin{abstract}
Una de las ventajas -escribe Rubén Darío- que han tenido nuestras dos últimas generaciones es la de la comunicación y mutuo conocimiento. Si aún algo queda que desear, ya no sucede como antaño, que se ignorasen, de nación a nación, los seguidores de una misma corriente filosófica o estética /... / Hay mayor intercambio de ideas. Se comunican los propósitos y las aspiraciones. Se cambian los estímulos. Hay muchas simpatías trocadas y muchas cartas. Los imbéciles no evitan en afirmar: sociedad de elogios mutuos. No se hace caso a los imbéciles. Los libros y las cartas se siguen trocando. No otra cosa se hacía en latín, entre los sabios humanistas del Renacimiento. (Darío, 1951, 117)
\end{abstract}

Si la lengua remeda a los puntos que unidos arman la constelación del espacio ideal de la inteligencia, la creación y la solidaridad, la carta es uno de los medios mediante el cual la materialización de "la patria intelectual" se hace posible. Demás está insistir, entonces, en la relevancia de este género discursivo para la reconstrucción de los circuitos de intercambio, que se dan hacia el interior de la red de escritores. Además de la carta, el periodismo ejerció una función primordial en la creación y la transmisión de un imaginario recíproco. Sin embargo, el intercambio era extremadamente desigual:

Los periódicos españoles traían noticias de Francia, Inglaterra, Italia y otros países europeos, pero casi nada de América o sobre América. El español común no tenía sino los más vagos conocimientos de la geografía, la política y el ambiente social de las nuevas naciones, en espacial de las más pequeñas. Si llegaba alguna vez a fijarse en ellas, la era difícil distinguir entre Guatemala y Honduras, entre 
Teoría y práctica de la "patria intelectual". La comunidad transantlántica en la conjunción de cartas, revistas y viajes / Dr. Claudio Maíz

Paraguay y el Uruguay. Su visión de América era la de una vasta región de selvas malsanas donde abundaban las fieras, los insectos y las serpientes venenosas, donde la gente era revoltosa y la política tormentosa. (Fogelquist, $1967,19)$

En efecto, los que salían desfavorecidos, como puede apreciarse, son los hispanoamericanos, por el deformado imaginario que se ideaba en la península y obraba como base de un conjunto de prejuicios en torno a la cultura y el arte hispanoamericanos ${ }^{9}$. Aun con este dato negativo, España, de manera involuntaria, contribuía a reparar la secular incomunicación entre hispanoamericanos. Los resultados, en cambio, en las relaciones intra-americanas eran diferentes.

Además de producir fenómenos de coetaneidad -escribe Zanetti- en América latina por el desarrollo simultáneo de similares condiciones de producción y recepción, la prensa se constituye en el principal agente de religación del período, pues promueve una red extensa e intensa de vínculos entre los latinoamericanos, escritores y público. (Zanetti, 1994, 514)

Por su lado, Wayne Ashhurt al referirse a la actuación de Rubén Darío en España, le atribuye un papel crucial a la ex metrópoli, ya que, de no haber sido desde allí, el reconocimiento europeo del nicaragüense no habría llegado. Otro saldo favorable que reconoce tiene que ver con lo que los críticos españoles de entonces decían: "que los escritores americanos no se conocían directamente, sino que se mantenían en contacto a través de España; que se ignoraban entre sí y conocían mejor a los españoles que a los mismos americanos de otros países" (Wayne Ashhurt, 1980, 594) $)^{10}$. Hasta 1898, la información era mala, a excepción del tratamiento que se hacía de Cuba y Puerto Rico, por el hecho de que seguían siendo colonias, pero tampoco podría decirse que era buena en lo que concierne al movimiento cultural de esas áreas. Este orden de cosas no varía con la

9 "La actitud 'normal' de los escritores españoles del siglo XIX con referencia a las letras hispanoamericanas había sido desconocerlas o estigmatizarlas por sus pretendidos 'errores' (históricos, ideológicos, gramaticales, ortográficos, etc.) y, ante todo, por la falta de aceptación del casticismo y su preferencia por la extranjerización (en aquellos tiempos, sobre todo galicista) /.../" (Rama, 1982: 301)

10 Por su parte, dice Carlos Rama sobre los viajeros latinoamericanos en Europa: "No debe olvidarse que las comunicaciones, en lo que se refiere al transporte, mercancías y pasajeros, eran más eficaces, económicas y frecuentes entre los países latinoamericanos con París, Londres, Nueva York, Madrid o Barcelona, que entre los mismos estados americanos; y dado el carácter de intelectuales de muchos de estos viajeros, era posible que durante sus estancias en España establecieran contactos, conocimientos amistades entre sí." (Rama, 1982: 271-272) 
pérdida de las últimas colonias. La prensa española seguirá abundando en temas europeos o locales españoles (Rama, 1982, 242).

Con todo, si la "comunidad imaginada" hispano-americana a través de la prensa española resultaba a la postre extremadamente deficiente, existirán otras iniciativas que tendrán un valor compensatorio, como el de las revistas. La lista es extensa, valgan estos ejemplos: "La España Moderna" [1880-1914]; "Vida Nueva" [1898-1900], "Revista de España, de Indias y del Exterior" [1842-1845], "El Imparcial. Revista Hispanoamericana" [1867-1869], "La Ilustración Española y Americana" [1869-1921], "El Correo de Ambos Mundos" [1869-?], "Unión Iberoamericana (Revista oficial de la Unión Iberoamaericana)" [1898-?], "Revista de Crítica de Historia y Literatura Española, Portuguesa e Hispanoamericana" [1899-?]. Este conjunto de publicaciones periódicas es suficientemente ilustrativo de la relevancia que tiene la prensa española especializada en temas latinoamericanistas o hispanoamericanistas, circunstancia que no se equipara del otro lado del Atlántico, al menos con la misma intensidad. Por otro lado, a la construcción imagológica sobre España contribuyen las corresponsalías y escritos de autores "transplantados" (Henríquez Ureña, $1952,57)$ que dan a la prensa hispanoamericana, además de los libros de viajes que reflejan de manera episódica y personalizada los pormenores de la sociedad y la cultura peninsular. (Henríquez Ureña, 1952, 259)

\section{Los epistolarios}

Ahora bien, el otro medio de fuerte incidencia para la comunidad intelectual imaginada es la carta. Las relaciones epistolares ayudan a establecer una comunidad virtual, en razón de que existe un eje que las vertebra. La cultura constituye la trama que engarza el conjunto de voces dispersas, que se reúnen en un oikos de la inteligencia y la sensibilidad, a la manera de una topofilia. Así imaginan la "patria intelectual" los letrados del periodo que estudiamos. El nuevo mapa que fragua el interés por la cultura perfora las fronteras y amplifica los horizontes, puesto que existe hacia finales del siglo XIX y principios del XX una extremada confianza en el poder transformador de la cultura.

En tal sentido, nuestro interés por los epistolarios (Maíz, 1996, 1999, 2005) estriba en el hecho de que su estudio contribuye a la reconstrucción de las redes que escritores, artistas e intelectuales han propiciado. El interés se centra asimismo en el impacto que estas lógicas de enlaces poseen en la formación de imaginarios colectivos dentro de la cultural hispánica. Una lectura de las constelaciones públicas y privadas y su huella en la formulación de autoimágenes regionales, continentales y/o trasnacionales favorece no sólo la indagación de las lógicas de enlaces, 
Teoría y práctica de la "patria intelectual". La comunidad transantlántica en la conjunción de cartas, revistas y viajes / Dr. Claudio Maíz

sino además la confección de un mapa de las imágenes que se forjan hacia el interior de aquellas constelaciones. Más aún, las imágenes existentes han sido siempre un marco de referencia implícito para el intercambio cultural y las relaciones culturales efectivas. ${ }^{11}$

Hemos descrito la "patria intelectual" como lo contrario de un reducto de nacionalismos estrechos, asimismo como un espacio desde donde se pretende tender nexos no sólo hacia otras literaturas sino también a la cultural universal. En su interior se percibe un aire expansivo. No obstante, no existe consenso sobre las vías para el intercambio simbólico con otros espacios. ¿Cuáles son los movimientos estratégicos que emprenden los sujetos letrados para tender ligamentos con la cultura universal, identificada casi estrictamente con Europa? Dicho de manera sintética, los movimientos van de la apertura al ensimismamiento, fundamentalmente. En los años que van de 1810-1898 surge América Latina como una entidad cultural autónoma, "con una alta conciencia de su identidad y unidad interna, $y$, ante todo, de sus distancias y diferencias con la metrópoli." Según Carlos Rama, el factor por excelencia "para explicar la separación del nuevo mundo de su matriz europea ha sido el aislamiento" principalmente cultural, y esto tiene que ver con la actitud de la misma España oficial, de sus órganos oficiales de cultura y, en definitiva, de su endémica crisis decimonónica. En su aislamiento la América Hispana generó rasgos nuevos y "se integró en mayor escala que la misma ex metrópoli a las corrientes cosmopolitas, viviendo experiencias propias" (Rama, 1982, 10). Aun dentro de la incomunicación experimentada hasta la renuncia de España a sus sueños de "reconquista" (1866) y más allá todavía de esa instancia, hubo puentes tendidos que buscaron lograr una mutua comprensión.

\section{Conflictos de la comunidad imaginada}

Los intentos por reestablecer los vínculos hispano-americanos se intensifican con el cambio situacional de América Latina y España luego de la guerra de Cuba en 1898. El nuevo escenario, ocupado por la preponderancia de los Estados Unidos, propicia el reencuentro, en algunos casos o el redescubrimiento en otros. De resultas de la marginación común, se intensifican también los contactos culturales y comienzan a

11 González Pizarro agrega al tema de las fuentes para el estudio de las relaciones intelectuales, las bibliotecas, las memorias, los diarios de viajeros y periodistas, las revistas literarias, instituciones intelectuales, la actividad diplomática. Respecto de las bibliotecas, dice que su estudio "ha permitido conocer el comercio de libros, fluctuaciones de autores y títulos entre las variadas bibliotecas americanas y examinar el estado intelectual de acuerdo a la época, en determinadas localidades" (González Pizarro, 1987: 128) 
gestarse búsquedas semejantes. Como por ejemplo la de conformar un espacio literario de contextos más amplios que los dados por las marcas nacionales, según hemos visto. Más específicamente, se abre una pugna por la formación de un espacio literario transnacional. ¿Cómo se da este debate en el contexto que describimos? Uno de los hilos de esta trama lo aporta José Martí:

\begin{abstract}
Vivimos, los que hablamos lengua castellana, llenos todos de Horacio y de Virgilio y parece que las fronteras de nuestro espíritu son las de nuestro lenguaje ¿Por qué nos han de ser fruta casi vedada las literaturas extranjeras, tan sobradas hoy de ese ambiente natural, fuerza sincera y espíritu actual que falta en la moderna literatura española? Ni la huella que en Núñez de Arce ha dejado Byron, ni la que los poetas alemanes imprimieron en Campoamor y Bécquer, ni una que otra traducción pálida de alguna obra alemana o inglesa bastan a darnos idea de literatura de los eslavos, germanos y sajones /... / Conocer diversas literaturas es el medio mejor de libertarse de la tiranía de algunas de ellas /.../. (Martí, 1882)
\end{abstract}

El internacionalismo de Martí, en materia literaria, es un esfuerzo por reunir la recomposición de los vínculos de Hispanoamérica con el resto de Occidente, por un lado, y la preservación de los elementos propios, a través de una relación de tipo igualitaria con la literatura mundial ("Weltliteratur"), por el otro. No es otra, nos parece, la razón por la cual Ángel Rama lo sitúa en el eje de la modernización, ya que el "imperialismo de la cultura francesa" no puede combatirse fronteras adentro, en un ensimismamiento de rezagos románticos o componentes conservadores, ni tampoco prolongando la dependencia con la cultural española, sino siendo más internacionalistas, es decir, "mediante una audaz ampliación del horizonte universal de la cultural" (Rama, 1983, 95). El internacionalismo martiano asimismo va en dirección opuesta a los dispositivos normativos que los procesos de constitución de las literaturas nacionales ponen en juego. Mediante tales dispositivos se busca una homogeneización de los imaginarios que tiendan a la preservación de identidades circunscritas a una frontera política.

La "patria intelectual" o espacio transnacional demarcado por la lengua parece el más productivo, ya que la ampliación de la mirada despeja los peligros de un ceñimiento a los circuitos nacionales y ofrece una serie de elementos comparativos que permiten el trabajo tanto contrastivo como de hallazgo de analogías entre diversas áreas. El espacio transnacional constituye entonces un dato probado en el contexto que estudiamos, tanto por parte de algunos hispanoamericanos -la noción de "patria 
Teoría y práctica de la "patria intelectual". La comunidad transantlántica en la conjunción de cartas, revistas y viajes / Dr. Claudio Maíz

intelectual" pertenece a Rodó-, como del propio Miguel de Unamuno. Es conocida la participación en la prensa diaria hispanoamericana del escritor español, llevada a cabo además para dar respuestas al problema de España en su relación con Europa. La galofobia unamuniana no se origina solamente por la influencia krausista, sino también como consecuencia de la incursión del escritor español en el campo hispanoamericano. Esta lucha "tuvo una enorme influencia sobre su visión de lo que debía ser la relación entre España y Europa" (Roberts, 2000, 421).

La "patria intelectual" no está formada, pues, con fronteras fijas, inalterables, imperiales como las que provee, por ejemplo, un hispanismo conservador, que alienta la restitución de ciertas jerarquías fundadas en las glorias pasadas. Pretensión subyacente en algunas propuestas de entonces. Inaceptable para los hispanoamericanos, ansiosos de recorrer todo lo nuevo, lo exótico y lo lejano, características infinitamente distantes de España. Tal es su tara pero también su ventaja. Los escenarios de la actuación intelectual se piensan amplificados, en algunos casos, hasta el nivel ecuménico en el que también es posible el comercio intelectual, la relación amistosa, la empresa cultural, la solidaridad política, por encima de lengua materna. Entre los hispanoamericanos resulta casi natural por lo menos una segunda lengua, invariablemente el francés; incluso para Unamuno la penetración de otras culturas solamente se hace aprendiendo su idioma. Así piensa a la hora de estudiar el danés, entre otras lenguas que maneja y conoce. La "patria intelectual" expande sus límites a fin de abrirse a la circulación de ideologías estéticas, técnicas lingüísticas de expresión literarias, lecturas, traducciones. Sin embargo, para que esta actividad sea efectiva -como se ha dicho- se requiere de los medios idóneos, sin los cuales sería impensable: la carta, la revista, el periódico. Pero debe insistirse también en el conocimiento de otras lenguas. Unamuno lo sabe y así lo recomienda junto con el viaje, dos maneras de romper los aislamientos espirituales. En carta a un joven intelectual, le dice respecto a una pregunta sobre un viaje al extranjero, es decir, "orearse por ahí fuera": "Eso depende de sus gustos y aptitudes de usted. El primer factor es la lengua; si usted fuese a Alemania o Inglaterra necesitaría todo el tiempo para aprender alemán o inglés, lo cual me parece que es bastante fruto" (Unamuno, 1991, 67). Juan Marichal piensa que Unamuno, para "conquistar" Europa, sólo podía hacerlo desde dentro "de sus idiomas, de su espíritu: y así se podría españolizar a Europa." La "conquista de Europa" significa "poder ser escuchado, en cuanto voz española, en el ámbito espiritual de las grandes capitales transpirineicas" (Marichal, 1998,18).

La nueva sensibilidad se ve acompañada de una pulsión expansiva que rebasa las limitaciones aldeanas, provinciales, nacionales y aun supranacionales: la cosmópolis aparece como el nuevo hogar del hombre 
letrado. Es una experiencia que se vive por igual en las áreas periféricas, que consiste en salir del "pequeño mundo" con el fin de hallar vivencias más estimulantes.

Vivencias claves -escribe Zanetti- de la universalización de experiencias culturales; "unificación del mundo", que vuelve semejantes los problemas del hombre en la vida moderna, y en nuestro caso del escritor, que compartía no la "influencia" o el reflejo de procesos o textos extraños, sino los conflictos, las presiones y los deseos del artista y del intelectual de los distintos ámbitos de Occidente. La puesta en escena de este marco cosmopolita permite diseñar la flexión propia, americana, esa que, con insistencia, se pretendía reducir a tópicos convencionales americanos, encerrándola en una "eterna silva a la agricultura de la zona tórrida" (Zanetti, 1994, 494).

La experiencia expansiva de la vida moderna acarrea serios y hasta enconados debates sobre la manera de permitir su ingreso. Aunque es el signo ineludible de la época ${ }^{12}$. ¿La clave está en la indiscriminada apertura, aun a riesgo de perder los signos de identificación, en el amurallamiento defensivo o bien en la afirmación de "lo propio" con vistas a confrontarlo con "lo ajeno"? La "patria intelectual" se convierte a la postre en una alternativa válida, situada entre el encierro de lo nacional y la ciudadanía mundial. Los dilemas, sin embargo, no eran ni lejos nuevos. El cosmopolitismo, un vocablo de claras resonancias gálicas, llega a Hispanoamérica con la acepción más generosa y altruista, a través de la Ilustración española. Juan Montalvo editará un periódico titulado El Cosmopolita [Montalvo 1866-1869]. En el último lustro del XIX, aparece en Venezuela la revista Cosmópolis, en la que participa lo más granado de la intelectualidad de entonces: Pedro Emilio Coll, Rubén Darío, Enrique Gómez Carrillo, Pedro César Dominici. Merece destacarse el objetivo que identifica a la revista: "(ser) campo de expresión a los escritores jóvenes venezolanos y establecer conexiones con escritores de otras latitudes." Pedro Emilio Coll será aún más explícito al definir la revista: "Abogamos por la solidaridad humana y la literatura es uno de los medios por los que ella se establece"13. Como se puede observar, la literatura entendida como una extensión de la cultura ocupa el lugar de enlace solidario entre los

12 El peruano Francisco García Calderón escribió en 1913: "nuestra edad organiza fuerzas aisladas en todos los órdenes del pensamiento y de la acción". Ejemplificando primero con casos de las ciencias y la filosofía, insiste luego: "grandes movimientos internacionales tienden a destruir las fronteras: el socialismo y el sindicalismo, las uniones de clase, los trust del capitalismo feudal, [así como] desinteresadas agrupaciones científicas florecen". (García Calderón, 1979: 223).

13 Para este tema véase: (Salomón, 1986: 173-199) 
Teoría y práctica de la "patria intelectual". La comunidad transantlántica en la conjunción de cartas, revistas y viajes / Dr. Claudio Maíz

que la practican o disfrutan. Este enorme optimismo respecto del poder de las bellas letras está en plena vigencia. La fuerza pedagógica que se le imprime proviene de mucho tiempo antes: desciende de aquella literatura didáctica medieval, que habrá de continuarse a lo largo del Renacimiento, bajo la forma del humanismo y en el siglo XVIII, la literatura no se limitaba a incorporar ciertos valores, sino que "era un instrumento para que arraigase y se diseminaran más" (Eagleton, 1988, 29) ${ }^{14}$.

Frente al cosmopolitismo, se alzan dos posturas diferentes: obviamente, los defensores de un arte nacional o regional, criollista, incluso y los que alientan una conexión con otras culturas, pero desde una instancia internacionalista. No puede dejar de considerarse también una fase intermedia, que aplaza en el tiempo la realización de la utopía mundialista. Así por ejemplo, Manuel Ugarte aseguraba que como "demócrata" era partidario de la "unión universal", poniendo toda su confianza "en el advenimiento de una época feliz que reconcilie a los hombres bajo una misma bandera" (Ugarte, 1953,109). Mientras ese tiempo llega, es deber ineludible el de "salvaguardar la independencia colectiva", ya que la acumulación de los grandes imperios es "la negación de la libertad" (Ugarte, 1953,110), alega el escritor argentino pensando en el imperialismo norteamericano.

De manera que cierto tipo de internacionalismo y el cosmopolitismo en América Latina constituyen registros abstractos y utópicos, derivados de la tradición europea de las Luces (Salomon, 1986, 176). En cambio, hubo voces previsoras que veían con preocupación una apertura cultural indiscriminada y sin apoyos sólidos, es decir, sin tradición propia, como el internacionalismo de José Martí, al que nos hemos referido. De acuerdo con los principios martianos, la integración hispanoamericana, debe alentarse desde una base popular consistente y tomando en cuenta los legados prenacionales heredados de la época colonial (virreinatos, capitanías, intendencias). Su internacionalismo continental americano conlleva el respeto a las nacionalidades constituidas. Nuevamente el arte y la cultura juegan aquí un papel preponderante en su ensamble con la territorialidad. Para Martí: "No hay letras que son expresión, hasta que no hay esencia que expresar en ellas. Ni habrá literatura hispanoamericana hasta que no haya Hispanoamérica" (Martí, 1975, 164). Pocos años después, en clara coincidencia, en cuanto al reunir el territorio y la escritura, Ugarte escribirá:

14 Continúa Eagleton: “Creció la importancia de la literatura porque hacía falta buscar la unión de las clases medias, cada vez más poderosas pero espiritualmente burdas, con la aristocracia gobernante; difundir las buenas maneras, los gustos 'correctos' y las normas culturales de aceptación cultural. Esto incluía un conjunto de instituciones ideológicas: publicaciones periódicas, cafés, tratados de estética y cuestiones sociales, sermones, traducciones de autores clásicos, manuales de moral y urbanidad" (Eagleton, 1988: 29). 
Para poseer verdaderamente un territorio, no basta imponerle límites y clavar una bandera. Es indispensable ante todo traer a la superficie las posibilidades de realización que duermen dentro de él; y después de dignificarlo, enriquecerlo y fecundarlo con la inteligencia, darle por fin una fisonomía, imponerle un alma y transformarlo en una especie de ser viviente. La tierra, como el papel, sólo vale por lo que escribimos encima. (Ugarte, s/a, 17)

En virtud de lo cual, se podría decir que existe un internacionalismo sobre las relaciones entre naciones, en la que se inscriben José Martí y también Manuel Gutiérrez Nájera, entre otros ${ }^{15}$, y, por otro lado, un internacionalismo obrero, de procedencia marxista y anarquista. Habría también una vertiente internacionalista en el arte, como consecuencia de una falta de desarrollo de la nacionalidad, ambas afectadas por la incertidumbre: "La literatura hispano-americana ha tenido que reflejar esa incertidumbre de carácter. ¿Cómo dar a la novela o al verso rasgos propios, cuando todavía no los tiene la nación en que se producen? De ahí que los hispano-americanos cultiven en cierto modo un arte internacional /.../" (Ugarte, s/a: 151) Ante la falta de una tradición intelectual sólida, los latinoamericanos deben estar atentos a lo producido en otros espacios Así lo ve Ugarte: "Comprendo que una nación de abolengo y pasado se defienda de la influencia extranjera; pero un pueblo en formación, ¿no tiene acaso el deber de adoptar lo bueno de los demás, de acumular en su alma la excelencia de los otros, de hacerse?" (Ugarte, $s / a, 151)$ Aunque este espíritu universalista que anima la idea ugarteana procura la asimilación, que es algo bien distinto de "pensar con cerebro ajeno" (Ugarte, s/a: 21-22) ${ }^{16}$.

Hay un internacionalismo coincidente entre el mencionado José Martí, Manuel Ugarte y también Rubén Darío. En los tres casos la nacionalidad

15 La estética innovadora está en los comienzos del modernismo. Gutiérrez Nájera, en 1894, recomienda que "Conserve cada raza su carácter substancial; pero no se aísle de las otras ni las rechace, so pena de agotarse y morir". Gutiérrez Nájera, 1959: 102) Esta interrogación, formulada por Martí, en 1882, evidencia la intensidad de la preocupación: “¿Por qué nos han de ser fruta casi vedada las literaturas extranjeras, tan sobradas hoy de ese ambiente natural, fuerza sincera y espíritu actual que falta en la moderna literatura española." (Martí, 1975: 361)

16 El problema de asimilación del pensamiento extranjero ya es un debate intenso en la mitad del siglo XIX. Acusado de plagio en un discurso pronunciado en 1842, a propósito de la creación de la Sociedad Literaria, escribe Lastarria: "Este achaque de los que, pretendiendo ser siempre orijinales, no comprenden el importante papel que en pueblos atrasados hacen los escritores que reproducen ideas ajenas, las generalizan o vulgarizan, /.../ No nos arrepentiríamos de haberlos hecho, ni jamás nos arredramos de reproducir las ideas ajenas que se nos han grabado en la memoria, olvidando a sus autores, porque tratamos de enseñar la verdad, sin afectar erudición..." (Lastarria, 1912: 140). 
Teoría y práctica de la "patria intelectual". La comunidad transantlántica en la conjunción de cartas, revistas y viajes / Dr. Claudio Maíz

irrealizada, la ausencia de una tradición, entre otros obstáculos, sitúa a la literatura en un lugar receptivo, asimilativo. Podría decirse que el internacionalismo que practican integra los parámetros de lo abierto. No obstante para el caso de la difusión y el reconocimiento de la obra la demarcación nacional es determinante. ¿Quiénes son los internacionales para Ugarte? En una carta a su hermano y a propósito de su exclusión del premio nacional de literatura de la Argentina, escribe:

Ya sé que me vas a tachar de vanidoso, pero los escritores de América que circulan conjuntamente con los grandes escritores de España son: José Vasconcelos, Francisco García Calderón, Rufino Blanco Fombona, Alfonso Reyes, Gabriela Mistral, y yo, único argentino entre los vivos. Entre los muertos: Amado Nervo, Rubén Darío, Gómez Carillo, José Ingenieros y José Enrique Rodó. Todo lo demás es favoritismo local, telón pintado de teatro de aldea. (Ugarte, 1999, 124-125)

\section{Palabras finales}

¿Cuál es el papel activo de intelectuales como Manuel Ugarte en la configuración de una comunidad imaginada de las elites intelectuales latinoamericanos? En una carta de José Enrique Rodó a Ugarte escrita en abril de 1896 (recuérdese que es el mismo año en el uruguayo plantea la idea de "la patria intelectual") pondera, de la Revista Literaria-la publicación que dirige el argentino-, la "internacionalidad americana" que la define. Rodó entiende que ello se ha logrado gracias al "concurso solicitado y obtenido de personalidades que llevan a sus páginas la ofrenda intelectual de diversas secciones del Continente."(Rodó, 1967, 831) Publicaciones como la Ugarte, en la consideración de Rodó, no harán sino que se "acabe el actual desconocimiento de América por América misma; merced a la concentración de las manifestaciones, hoy dispersas, de su intelectualidad, en un órgano de propagación autorizado" (Rodó, 1967, 831) La situación del argentino no es muy diferente a la de hombres de letras del periodo, esto es, su caso debe pensarse en vinculación con otros similares. Nos referimos a Rufino Blanco Fombona y Rubén Darío por tomar dos ejemplos significativos. En todos la labor periodística, propagandística, viajera y de creación y dirección de publicaciones resulta común. Sin embargo, la amplitud de horizontes constituye una preocupación poco común entre la intelectualidad de la época. ¿Qué debe entenderse por ello? En primer término que no son tantos los interesados en abandonar del ámbito nacional como punto de referencia. Entre los que así actúan, se implanta un pensamiento estético y literario que toma a la nacionalidad, la naturaleza americana y lo típico como materia prima de la creación 
que pueda ser de interés fuera del espacio propio. "Y en literatura, todo lo nuestro es irremediablemente tropical o cubano. Nuestros poetas les evocan un pájaro y una fruta: el sinsonte y la guayaba.", dice Darío sobre el conocimiento que se tiene de la literatura hispanoamericana en Europa. (Darío, 1951, 123) En cambio, el pelotón de escritores que se desmarca de la nacionalidad como medida de la creación original busca denodadamente la amplitud de horizontes, forjando espacios transnacionalizados. Solamente de ese modo, entienden estos escritores, será factible participar del pensamiento, la creación, la divulgación de obras, el trato intelectual con los centros culturales de mayor productividad y prestigio. Como se ve, habitar en una "patria intelectual" que vaya más allá de la "patria política y soberana" no es un trámite sencillo. Se puede decir que en el fondo de esta ampliación o reducción de horizontes se ubica el asunto primordial de la cultura hispanoamericana de entonces, cual es, el de la originalidad. De ahí que sea conveniente no olvidar a José Martí y su propuesta de una internacionalización hispanoamericana basada en la autoafirmación y conocimiento de las cosas americanas.

Con todo, la constitución de una transnacionalidad intelectual, tal como la bosquejaron el uruguayo José Enrique Rodó, el argentino Manuel Ugarte, el nicaragüense Rubén Darío y español Miguel de Unamuno no se orientaba exclusivamente hacia América sino que por el contrario comprendía a España. Incluso en los casos de Rodó y Darío la amplitud va mucho más allá de esos confines. La comunidad intelectual transatlántica iberoamericana durante el periodo que hemos delimitado tuvo muchas sedes importantes en la gestación y desenvolvimiento del espacio trasatlántico, la ciudad de Salamanca a través de la figura de Miguel de Unamuno, empero, resultó una de las más destacadas. No ciertamente porque el aparato estatal salmantino o su prestigiosa universidad hayan tenido un papel recordable, sino por las vínculos literarios y amistosos tendidos entre los hispanoamericanos y Unamuno.

\section{Bibliografía}

Anderson, Benedict, 1997. Comunidades imaginadas. Reflexiones sobre el origen y la difusión del nacionalismo, trad. Eduardo Suárez, México: Fondo de Cultura Económica.

Arpini, Adriana, Maíz, Claudio, 2007.

Hilar ideas. Travesías del pensamiento en América Latina, Mendoza: Centro de Estudios Trasandinos, Universidad Nacional de Cuyo.

Darío, Rubén, 1951. "El Brasil intelectual", Rubén Darío. Crítico literario. Temas americanos, selec., pról., notas de Emilio 
Teoría y práctica de la "patria intelectual". La comunidad transantlántica en la conjunción de cartas, revistas y viajes / Dr. Claudio Maíz

Abreu Gómez, México: Unión PanamericanaWashington.

Devés-Valdés, Eduardo, 2007.

Redes intelectuales en América Latina. Hacia la constitución de una comunidad intelectual, Santiago de Chile: Instituto de Estudios Avanzados, Universidad de Santiago de Chile.

Díaz Plaja, Guillermo, 1971. Al filo del novecientos. Estudios de intercomunicación hispánica, Barcelona: Editorial Planeta.

Eagleton, Ferry, $1988 . \quad$ Una introducción a la teoría literaria, Trad. José Estaban Calderón, México: Fondo de Cultura Económica.

Even-Zohar, Itamar. 1997. "Factores y dependencias en la cultura. Una revisión de la teoría de los polisistemas", Teoría de los polisistemas. comp. y traducción: Montserrat Iglesias Santos, Madrid:. Arco/Libros.

Fogelquist, Donald F. y Anna Wayne Ashurt, 1968.

Españoles de América y americanos de España, Madrid: Gredos.

García Calderón, Francisco. 1979,

La creación de un continente, Ayacucho: Caracas.

Gil Fortoul, J., 1957.

Obras completas, Caracas: Ministerio de Educación.

González Pizarro, José Antonio, 1987.

"Fuentes, propósitos y perspectivas para el estudio de las relaciones literarias entre España e lberoamérica. Algunas notas", Las relaciones literarias entre España e Iberoamérica, Madrid: Instituto de Cooperación Iberoamericana, Facultad de Filología, Universidad Complutense.

González Stephan, Beatriz, 1987.

La historiografía literaria del liberalismo hispanoamericano en el siglo XIX, La Habana: Ediciones Casa de las Américas.

Gorelik, Adrián, 2004. “El comparatismo como problema: una introducción", Prisma. Revista de historia intelectual, Buenos Aires: Universidad de Quilmes, n. 8.

Gramuglio, María Teresa, 2006.

"Tres problemas para el comparatismo", Orbis Tertuis, XI (12). 
Gutiérrez Nájera, Manuel, 1959.

$$
\begin{aligned}
& \text { "El cruzamiento en literatura", Obras I. Crítica } \\
& \text { literaria, México: UNAM. }
\end{aligned}
$$

Halperín Donghi, Tulio, 1998.

"España e Hispanoamérica: miradas a través del Atlántico (1825-1975)", en: El espejo de la historia. Problemas argentinos y perspectivas latinoamericanas, Buenos Aires: Sudamerican.

Henríquez Ureña, Pedro, 1952.

"La América Española", Plenitud de América.

Ensayos escogidos, Buenos Aires: Peña, Del

Giudice-editores.

Henríquez Ureña, Pedro, 1978.

La utopía de América, pról. Rafael Gutiérrez Girardot, comp. y cron. Ángel Rama y Rafael Gutiérrez Girardot, Caracas: Biblioteca Ayacucho.

Lastarria, J. V., 1912.

Obras Completas, Estudios Literarios, Primera Parte, Santiago de Chile: Imprenta, Litografía i Encuadernación "Barcelona”, v. X.

Maíz, Claudio, 1996. "La carta y el discurso autorreferencial. Aportes para una poética del género epistolar en Unamuno." Cuadernos de la Cátedra Miguel de Unamuno, Salamanca: Universidad de Salamanca, n. XXXI.

Maíz, Claudio, 1999. Cartas venezolanas a Miguel de Unamuno 19001933, prólogo, comp. y notas de Claudio Maíz, Salamanca: Ediciones Universidad de Salamanca.

Maíz, Claudio, 2005.

"Historia, literatura y lengua en el epistolario de Ricardo Palma y Miguel de Unamuno", Revista de Literaturas Modernas, Mendoza: Facultad de Filosofía y letras.

Mamontov, Stepán. Unamuno y Ortega: la variante española de la dicotomía rusa. Madrid: Instituto Cervantes y Ministerio de Cultura <http//hispanismo. cervantes.es/documentos/momontov.pdf> [consulta: 15 diciembre 2006]

Martí, José, 1975.

"Cuadernos de apuntes, 55 (1881)", Obras Completas, vol. 21, La Habana: Editorial de Ciencias Sociales.

Martí, José, 1882.

"Oscar Wilde", La Nación, Buenos Aires, 10-XII.

Marichal, Juan, 1998.

"Unamuno y su "Conquista de Europa"', Conrad Kent y María Dolores de La Calle, eds., Visiones 
Teoría y práctica de la "patria intelectual". La comunidad transantlántica en la conjunción de cartas, revistas y viajes / Dr. Claudio Maíz

Molina, Eugenia, 2007. "La red literaria como espacio de legitimación intelectual y recurso de proyección pública. El caso de La llustración Argentina (1849)", Arpini, Adriana, Maíz, Claudio, Hilar ideas. Travesías del pensamiento en América Latina, Mendoza: Centro de Estudios Trasandinos, Universidad Nacional de Cuyo.

Naciff, Marcela, 2007. "Las revistas de fin de siglo en Argentina, o dónde se relacionan los intelectuales modernistas", Arpini, Adriana, Maíz, Claudio, Hilar ideas. Travesías del pensamiento en América Latina, Mendoza: Centro de Estudios Trasandinos, Universidad Nacional de Cuyo.

Palti, Elías. 2004.

El problema de 'las ideas fuera de lugar' revisitado. Más allá de la 'Historia de las ideas', México: UNAM, Centro Coordinador y Difusor de Estudios Latinoamericanos.

Paredes, Alejandro, 2007. "Religión y exilio chileno. El discurso del Comité Ecuménico de Acción Social. Mendoza 19731989", Arpini, Adriana, Maíz, Claudio, Hilar ideas. Travesías del pensamiento en América Latina, Mendoza: Centro de Estudios Trasandinos, Universidad Nacional de Cuyo.

Rama, Ángel, 1983.

"José Martí en el eje de la modernización poética: Whitman, Lautréamont, Rimbaud", Nueva Revista de Filología Hispánica, t. XXXII, n. 1.

Rama, Ángel, $1985 . \quad$ "La ciudad letrada", Richard MORSE, Cultura urbana latinoamericana, Buenos Aires: CLACSO.

Rama, Carlos, 1982. Historia de las relaciones culturales entre España y la América Latina, Siglo XIX, México: F. C. E.

Reyes, Alfonso, 1959. "Última tule", Obras completas, México: Fondo de Cultura Económica, t. 11.

Roberts, Stephen, 2000. "El nacimiento de un prejuicio: 1898, América Latina y la galofobia", Cirilo Flórez coord., Tu mano es mi destino. Congreso internacional Miguel de Unamuno, Salamanca: Ediciones Universidad de Salamanca.

Rodó, José Enrique, 1967. "La novela nueva", Obras completas, ed., intr. y pról. Emir Rodríguez Monegal, Madrid: Aguilar. 
Salomón, Noel, $1986 . \quad$ "Cosmopolitismo e internacionalismo (Desde 1880 hasta 1940)", en Leopoldo Zea coord. e introd., América Latina en sus ideas, México: Siglo XXI.

Ugarte, Manuel, 1922. Mi campaña hispanoamericana, Barcelona: Editorial Cervantes.

Ugarte, Manuel, $1953 . \quad$ El porvenir de América Latina, Buenos Aires: Indoamérica.

Ugarte, Manuel, s/a. Las nuevas tendencias literarias, Valencia: Sempere.

Ugarte, Manuel, $1999 . \quad$ El epistolario de Manuel Ugarte (1896-1951), Buenos Aires: Archivo General de la Nación.

Unamuno, Miguel de, 1958. "José Asunción Silva", Obras completas, pról., ed. y notas de M. García Blanco, Madrid: Afrodisio Aguado, t. IV, Madrid: Aguado.

Unamuno, Miguel de, 1958. "Algo de unión ibero-americana", Obras completas, pról., ed. y notas de M. García Blanco, Madrid: Afrodisio Aguado, t. VIII.

Unamuno, Miguel de, 1991. Epistolario inédito (1894-1936), Madrid: Espasa Calpe.

Wayne Ashhurt, Anna, 1980. La literatura hispanoamericana en la crítica española, Madrid: Gredos.

Williams, Raymond. 1989. "Las percepciones metropolitanas y la emergencia del Modernismo", en., La política del modernismo. Contra los nuevos conformistas, comp. e intr Tony Pinkney, Buenos Aires: Manantial.

Zanetti, Susana, 1994. "Modernidad y religación: un perspectiva continental (1880-1916)", Ana Pizarro, América Latina: palabra, literatura e cultura, San Pablo: Memorial; Campinas: INUCAMP, v. 2 Emancipação do discurso.

Zanetti, Susana, $1998 . \quad$ "Apuntes acerca del canon latinoamericano", Susana Cella, comp., Dominios de la literatura. Acerca del canon. Buenos Aires: Losada.

Zuleta, Emilia, $1983 . \quad$ Relaciones literarias entre España y la Argentina, Madrid: Ediciones Cultura Hispánica del ICl. 